OPEN ACCESS

Edited by:

Guanglin Xia,

Fudan University, China

Reviewed by:

Teng He,

Chinese Academy of Sciences, China Hailiang Chu,

Guilin University of Electronic

Technology, China

*Correspondence:

Dongming Liu

Idm_ahut@163.com

Specialty section:

This article was submitted to

Nanoscience,

a section of the journal

Frontiers in Chemistry

Received: 14 February 2020

Accepted: 23 March 2020

Published: 15 April 2020

Citation:

Chen X, Li Z, Zhang Y, Liu D, Wang C,

Li Y, Si T and Zhang Q (2020)

Enhanced Low-Temperature

Hydrogen Storage in Nanoporous Ni-Based Alloy Supported $\mathrm{LiBH}_{4}$.

Front. Chem. 8:283.

doi: 10.3389/fchem.2020.00283

\section{Enhanced Low-Temperature Hydrogen Storage in Nanoporous Ni-Based Alloy Supported $\mathrm{LiBH}_{4}$}

\author{
Xi Chen, Zhao Li, Yue Zhang, Dongming Liu*, Chunyang Wang, Yongtao Li, Tingzhi Si and \\ Qingan Zhang
}

School of Materials Science and Engineering, Anhui University of Technology, Maanshan, China

To reveal the synergistic effect of nanoconfinement and metallic catalysis on the hydrogen storage properties of $\mathrm{LiBH}_{4}$, the nanoporous Ni-based alloy (np-Ni) was prepared herein by dealloying of the $\mathrm{Mn}_{70} \mathrm{Ni}_{30}$ alloy in $\left(\mathrm{NH}_{4}\right)_{2} \mathrm{SO}_{4}$ solution, and then $\mathrm{LiBH}_{4}$ was loaded into $\mathrm{np}-\mathrm{Ni}$ to construct the $\mathrm{LiBH}_{4} / \mathrm{np}-\mathrm{Ni}$ hydrogen storage system using wet impregnation. It was found that dehydrogenation of the $\mathrm{LiBH}_{4} / \mathrm{np}-\mathrm{Ni}(1: 5)$ system starts at around $70^{\circ} \mathrm{C}$ and ends before $400^{\circ} \mathrm{C}$, with $\sim 11.9 \mathrm{wt} . \%$ of hydrogen desorbed. The apparent dehydrogenation activation energy for the $\mathrm{LiBH}_{4} / \mathrm{np}-\mathrm{Ni}$ (1:5) system was remarkable decreased to about $11.4 \mathrm{~kJ} / \mathrm{mol}$. After rehydrogenation at $450^{\circ} \mathrm{C}$ under $8 \mathrm{MPa}$ hydrogen pressure, $\sim 8.2 \mathrm{wt} . \%$ of hydrogen can be released from about $60^{\circ} \mathrm{C}$ upon second dehydrogenation. These obtained results would provide an efficient strategy for improving the hydrogen storage properties of other metal borohydrides.

Keywords: hydrogen storage, lithium borohydride, nanoporous metal, nanoconfinement, catalysis

\section{INTRODUCTION}

Nowadays, the issue of energy shortage has been called into public focus. Hydrogen is considered to be the most ideal secondary source because of its high calorific value, low environmental impact and abundant resources (Abe et al., 2019). To meet the need of storing hydrogen with high efficiency and safety, it is necessary to develop hydrogen storage materials with high mass and volume hydrogen density (Yang et al., 2010; Li H. W. et al., 2011; Abdalla et al., 2018). $\mathrm{LiBH}_{4}$ has attracted much more attention due to its extremely high theoretical hydrogen storage capacity of $18.5 \mathrm{wt} . \%$. However, the elevated dehydrogenation temperature, complicated dehydrogenation behavior and poor reversibility limit its practical applications (Züttel et al., 2003; Orimo et al., 2005; Mauron et al., 2008; Li C. et al., 2011). In order to overcome these deficiencies, the strategies of constructing reactive hydride system (Liu D. M. et al., 2013; Liu et al., 2015, 2016; Ding et al., 2019), cation/anion substitution (Yin et al., 2008; Fang et al., 2011), adding catalyst (Zhang et al., 2017; Cai et al., 2018) and nanoconfinement (Guo et al., 2017; Xu et al., 2017; Meng et al., 2018) were developed in the last decade.

Nanoconfinement of $\mathrm{LiBH}_{4}$ in nanoporous material can maintain the particle within a nanoscale structure, which is exceedingly beneficial to enlarge the reaction interface and shorten the element diffusion distance, thus significantly enhancing the de-/rehydrogenation properties (Ngene et al., 2010b; Shao et al., 2015; Meng et al., 2018; Gasnier et al., 2019). For example, Zhang et al. found that $\mathrm{LiBH}_{4}$ nanoparticles supported by disordered mesoporous carbon (CMK-3) showed a single dehydrogenation peak at about $332^{\circ} \mathrm{C}$ and a large dehydrogenation amount of $14 \mathrm{wt} . \%$ below $600^{\circ} \mathrm{C}$ (Zhang et al., 2007). Fang et al. embedded $\mathrm{LiBH}_{4}$ into active carbon (AC) by chemical impregnation. 
Due to the enhancement of both the thermodynamic and kinetic properties, the $\mathrm{LiBH}_{4} / \mathrm{AC}$ system began to release hydrogen at $220^{\circ} \mathrm{C}$, which is $150^{\circ} \mathrm{C}$ lower than bulk $\mathrm{LiBH}_{4}$ without nanostructure modulation (Fang et al., 2008b). Other nanoporous material scaffolds, such as carbon aerogel (Zhao et al., 2014; Surrey et al., 2016), ordered mesoporous carbon (Cai et al., 2016), metallic organic framework (MOFs) (Sun et al., 2011) and mesoporous silicon dioxide (SBA-15) (Ngene et al., 2010a), were also used as the confinement carriers to support $\mathrm{LiBH}_{4}$.

However, the above reported nanoconfinement carriers are composed of non-metallic material that can only provide a single nanoconfinement role for $\mathrm{LiBH}_{4}$ in general. Taking into account that transition metal elements (e.g., $\mathrm{Ni}$ and $\mathrm{Co}$ ) can serve as the active catalyst in improving the hydrogen storage properties of complex hydrides owing to their high electronegativity0 (Ngene et al., 2011; Liu et al., 2018; Zhang et al., 2018), a synergistic effect of nanoconfinement and catalysis would be achieved by confining $\mathrm{LiBH}_{4}$ in nanoporous transition metal. Based on this consideration, nanoporous Ni-based alloy was prepared by dealloying of the $\mathrm{Mn}_{70} \mathrm{Ni}_{30}$ alloy and then used as the carrier to support $\mathrm{LiBH}_{4}$ in this work, and a significantly improved low-temperature hydrogen storage in $\mathrm{LiBH}_{4}$ was successfully obtained.

\section{EXPERIMENTAL SECTION}

\section{Sample Preparation}

Commercial $\mathrm{LiBH}_{4}$ powder (95\%, Alfa Aesar), Mn bulk (99.5\%, Alfa Aesar), Ni sheet (99.5\%, Alfa Aesar) and tetrahydrofuran (THF) (99.8\%, anhydrous, Alfa Aesar) were used in experiments. The $\mathrm{Mn}_{70} \mathrm{Ni}_{30}$ alloy was prepared by induction melting of appropriate amounts of $\mathrm{Mn}$ and Ni metals. For compensating the loss of Mn during melting, the extra 3 wt.\% of Mn was added on the basis of stoichiometric amount. The as-cast $\mathrm{Mn}_{70} \mathrm{Ni}_{30}$ alloy was mechanically crushed into powders of 200 mesh, and the nanoporous $\mathrm{Ni}$-based alloy (denoted as $\mathrm{np}-\mathrm{Ni}$ ) was prepared by dealloying of the $\mathrm{Mn}_{70} \mathrm{Ni}_{30}$ alloy powders in $1 \mathrm{~mol} / \mathrm{L}\left(\mathrm{NH}_{4}\right)_{2} \mathrm{SO}_{4}$ solution at $50^{\circ} \mathrm{C}$ for $2 \mathrm{~h}$. The $\mathrm{LiBH}_{4} / \mathrm{np}-\mathrm{Ni}$ (1:5) system was prepared by loading $\mathrm{LiBH}_{4}$ into np-Ni using wet impregnation method. Firstly, $\mathrm{LiBH}_{4}$ was dissolved in anhydrous THF. Then,
np-Ni was put in the $\mathrm{LiBH}_{4}$ solution according to the $\mathrm{LiBH}_{4} / \mathrm{np}$ $\mathrm{Ni}$ weight ratio of 1:5. Finally, the mixture was evacuated for $24 \mathrm{~h}$ to remove THF solvent.

\section{Sample Characterization}

De-/rehydrogenation properties were examined based on the volumetric method by using a carefully calibrated Sieverts-type apparatus. Thermal dehydrogenation was performed by heating the sample from ambient temperature to $500^{\circ} \mathrm{C}$ at a rate of $2^{\circ} \mathrm{C} / \mathrm{min}$. Isothermal dehydogenation was performed by quickly heating and then keeping the sample at a given temperature. The hydrogen back pressure for the above temperature ramp and isothermal dehydrogenation examinations was below $0.1 \mathrm{MPa}$. Isothermal rehydrogenation was carried out at $450^{\circ} \mathrm{C}$ under 8 $\mathrm{MPa}$ hydrogen pressure. The weight of np-Ni was not taken into account in calculating the hydrogen de-/absorption amounts.

$\mathrm{X}$-ray diffraction (XRD) measurement was performed by a Rigaku D/Max 2500VL/PC diffractometer at $50 \mathrm{kV}$ and $200 \mathrm{~mA}$ with $\mathrm{Cu} \mathrm{K} \alpha$ radiation. A special Ar-filled holder was applied to seal the XRD sample to avoid contact with air in the course of measurement. To quantitatively investigate the phase structure change of the $\mathrm{Mn}_{70} \mathrm{Ni}_{30}$ alloy before and after dealloying, the XRD profiles were analyzed with the Rietveld refinement program RIETAN-2000 (Izumi and Ikeda, 2000). Scanning electron microscopy (SEM) was carried out using a Nova NanoSEM 430 microscope equipped with an energy dispersive X-ray spectrometer (EDS). Transmission electron microscopy (TEM) observation was performed on a JEM-2100F instrument. Pore size distribution, pore volume and specific surface area were determined by a Micromeritics ASAP 2020 fully-automatic analyzer based on the Brunauer-Emmett-Teller (BET) and Barrett-Joyner-Halenda (BJH) methods (Lowell et al., 2004). Fourier transform infrared (FTIR) spectrum was collected using a Nicolet 6700 FTIR spectrometer.

\section{RESULTS AND DISCUSSION}

\section{Structural Analysis of $\mathrm{LiBH}_{4} / \mathrm{np}-\mathrm{Ni}$ System}

Figure 1 gives the observed XRD patterns and the Rietveld analysis results of $\mathrm{Mn}_{70} \mathrm{Ni}_{30}$ alloy before and after dealloying, and the phase abundances and structural parameters refined by
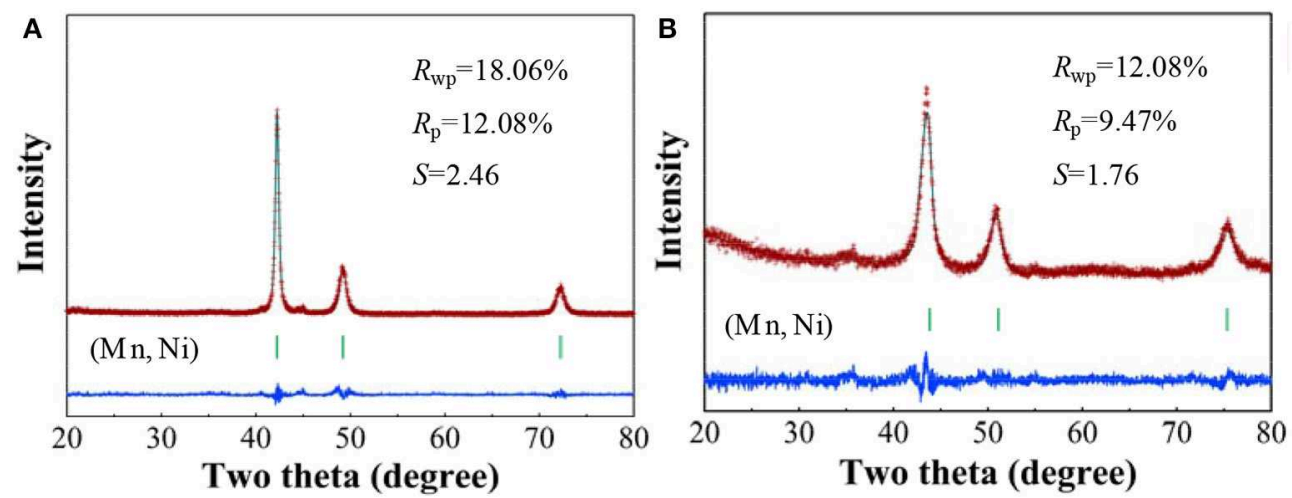

FIGURE 1 | Rietveld refinements of the observed XRD patterns for $\mathrm{Mn}_{70} \mathrm{Ni}_{30}$ alloy (A) before and (B) after dealloying. 
the Rietveld analysis are listed in Table 1 . It can be seen that the $\mathrm{Mn}_{70} \mathrm{Ni}_{30}$ alloy before and after dealloying are both composed of a single phase of $(\mathrm{Mn}, \mathrm{Ni})$ solid solution with a $\mathrm{Cu}$-type structure. However, the XRD peaks of $\mathrm{np}-\mathrm{Ni}$ are relatively broadened and move toward higher angle as compared with the $\mathrm{Mn}_{70} \mathrm{Ni}_{30}$ alloy. The results indicate that the grain size and cell parameters of the sample were both decreased with the extraction of Mn atom from $(\mathrm{Mn}, \mathrm{Ni})$ solid solution upon dealloying due to that $\mathrm{Mn}$ has a larger atomic radius relative to $\mathrm{Ni}$.

TABLE 1 | Phase components and structural parameters of $\mathrm{Mn}_{70} \mathrm{Ni}_{30}$ alloy and np-Ni.

\begin{tabular}{|c|c|c|c|c|c|c|}
\hline \multirow[t]{2}{*}{ Sample } & \multirow[t]{2}{*}{ Phase } & \multirow{2}{*}{$\begin{array}{l}\text { Space } \\
\text { group }\end{array}$} & \multicolumn{3}{|c|}{ Lattice parameters (Å) } & \multirow{2}{*}{$\begin{array}{c}\text { Abundance } \\
(\%)\end{array}$} \\
\hline & & & $a$ & $b$ & $c$ & \\
\hline $\mathrm{Mn}_{70} \mathrm{Ni}_{30}$ alloy & $(\mathrm{Mn}, \mathrm{Ni})$ & $F m-3 m$ & $3.6907(2)$ & $3.6907(2)$ & $3.6907(2)$ & 100 \\
\hline $\mathrm{np}-\mathrm{Ni}$ & $(\mathrm{Mn}, \mathrm{Ni})$ & $F m-3 m$ & $3.5601(1)$ & $3.5601(1)$ & $3.5601(1)$ & 100 \\
\hline
\end{tabular}

Figure 2 presents the SEM images and corresponding EDS spectra of $\mathrm{Mn}_{70} \mathrm{Ni}_{30}$ alloy and $\mathrm{np}-\mathrm{Ni}$. As seen from Figure 2A, the $\mathrm{Mn}_{70} \mathrm{Ni}_{30}$ alloy has a smooth surface with a particle size of about $\sim 70 \mu \mathrm{m}$. The EDS result (see Figure 2C) indicates that it consists of 70.22 at.\% $\mathrm{Mn}$ and 29.78 at.\% Ni, agreeing well with its nominal element composition. For $\mathrm{np}-\mathrm{Ni}$, as given in Figure 2D, the element content of $\mathrm{Mn}$ is decreased to 21.09 at.\%. It is reasonably considered that the massive lixiviation of $\mathrm{Mn}$ atom can bring large lattice distortion and physical shrinkage stress, thus leading to the formation of a nanoporous structure as shown in Figure 2B.

Figure 3A demonstrates the $\mathrm{N}_{2}$ adsorption/desorption isotherms for $\mathrm{np}-\mathrm{Ni}$ and the $\mathrm{LiBH}_{4} / \mathrm{np}-\mathrm{Ni}(1: 5)$ system. It can be seen that $\mathrm{np}$-Ni has a typical IV-type adsorption isotherm with an obvious hysteresis loop. Those are the characteristics of mesoporous material. In comparison, the hysteresis loop has almost disappeared for the $\mathrm{LiBH}_{4} / \mathrm{np}-\mathrm{Ni}$ (1:5) system. The pore size distributions of $\mathrm{np}-\mathrm{Ni}$ and the $\mathrm{LiBH}_{4} / \mathrm{np}-\mathrm{Ni}(1: 5)$ system are compared in Figure 3B, which indicates that the peak in pore size distribution of np-Ni moves to a lower position with
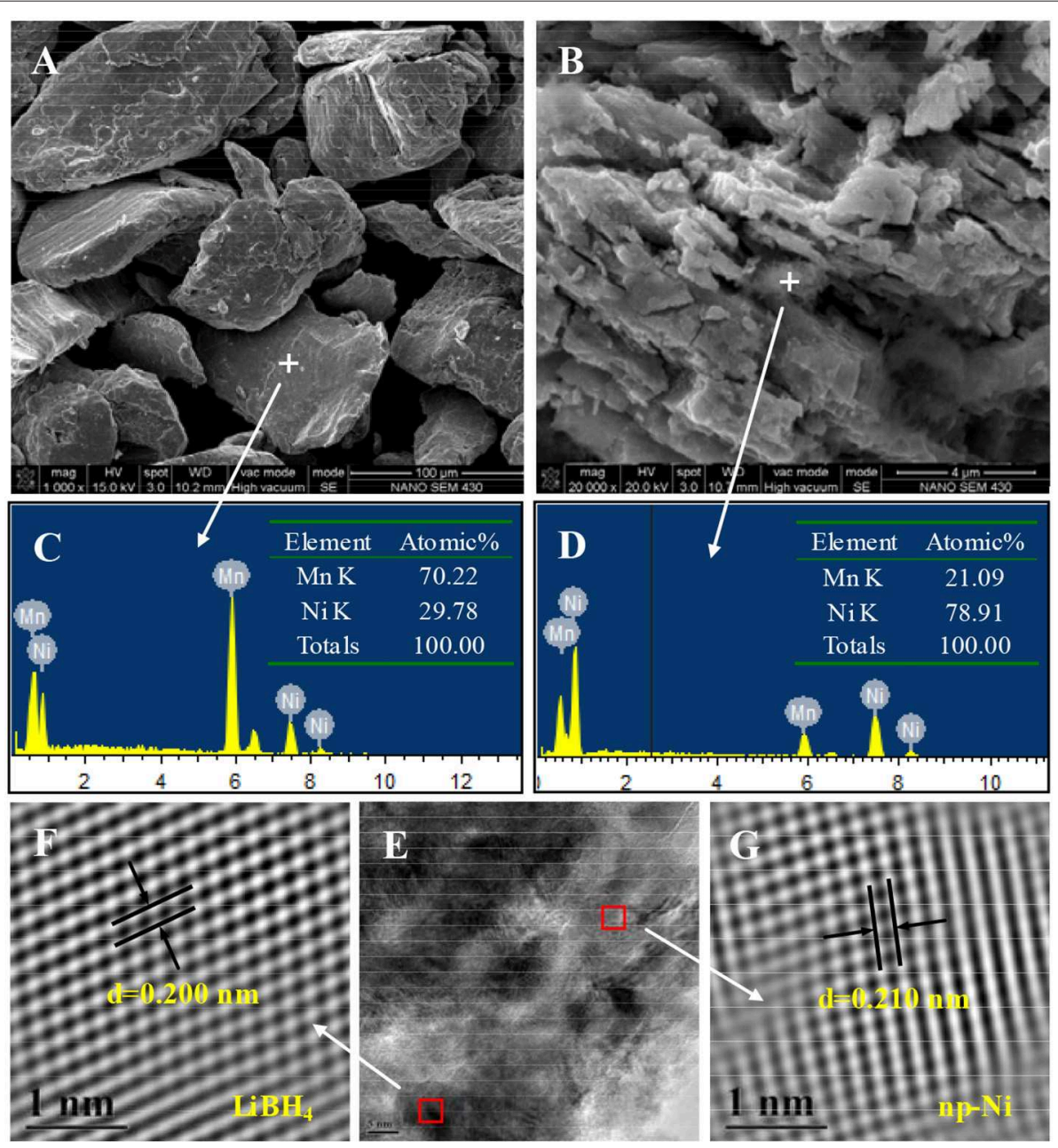

FIGURE 2 | SEM images and EDS spectra of (A,C) $\mathrm{Mn}_{70} \mathrm{Ni}_{30}$ alloy and (B,D) np-Ni; (E) TEM micrograph of the LiBH ${ }_{4} / \mathrm{np}-\mathrm{Ni}(1: 5)$ system and (F,G) atomic lattice images of the square regions in (E). 


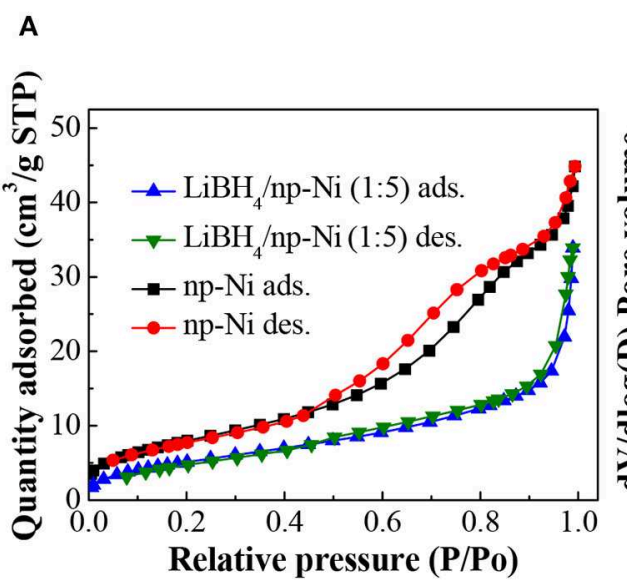

B

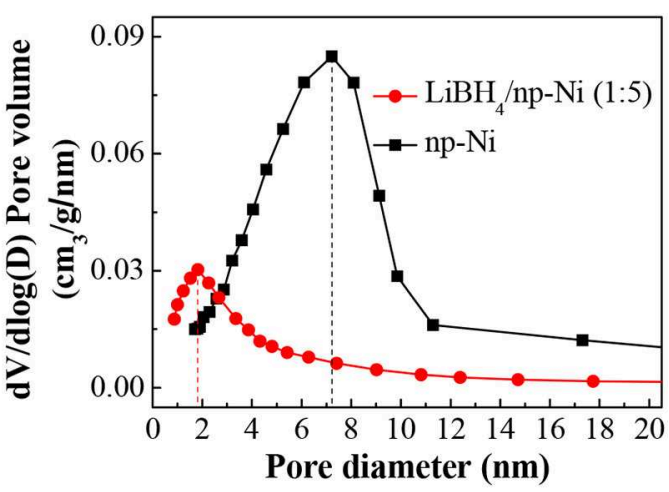

FIGURE 3 | (A) $\mathrm{N}_{2}$ adsorption/desorption isotherms and (B) pore size distributions of np-Ni and the LiBH $/ \mathrm{np}-\mathrm{Ni}$ (1:5) system.

TABLE 2 | Pore parameters and specific surface area of np-Ni and the $\mathrm{LiBH}_{4} / \mathrm{np}-\mathrm{Ni}(1: 5)$ system.

\begin{tabular}{|c|c|c|c|}
\hline Sample & $\begin{array}{l}\text { Pore size } \\
\quad(\mathrm{nm})\end{array}$ & $\begin{array}{l}\text { Pore volume } \\
\qquad\left(\mathrm{cm}^{3} / \mathrm{g}\right)\end{array}$ & $\begin{array}{l}\text { Specific surface area } \\
\qquad\left(\mathrm{m}^{2} / \mathrm{g}\right)\end{array}$ \\
\hline $\mathrm{np}-\mathrm{Ni}$ & 7.21 & 0.0586 & 155 \\
\hline $\mathrm{LiBH}_{4} / \mathrm{np}-\mathrm{Ni}$ & 1.80 & 0.0339 & 17 \\
\hline
\end{tabular}

an intensive decline in intensity after supporting $\mathrm{LiBH}_{4}$. Table 2 gives the pore parameters and specific surface area of np-Ni and the $\mathrm{LiBH}_{4} / \mathrm{np}-\mathrm{Ni}(1: 5)$ system. It is observed that $\mathrm{np}-\mathrm{Ni}$ has the pore diameter, pore volume and specific surface area of $7.21 \mathrm{~nm}$, $0.0586 \mathrm{~cm}^{3} / \mathrm{g}$ and $155 \mathrm{~m}^{2} / \mathrm{g}$, respectively. However, those values reduce to $1.80 \mathrm{~nm}, 0.0339 \mathrm{~cm}^{3} / \mathrm{g}$ and $17 \mathrm{~m}^{2} / \mathrm{g}$, respectively, for the $\mathrm{LiBH}_{4} / \mathrm{np}-\mathrm{Ni}(1: 5)$ system. These results imply that $\mathrm{LiBH}_{4}$ was loaded on the surface and impregnated into the pores of $\mathrm{np}-\mathrm{Ni}$. Figure $2 \mathrm{E}$ gives the TEM micrograph of the $\mathrm{LiBH}_{4} / \mathrm{np}-\mathrm{Ni}$ (1:5) system, and Figures 2F,G present the atomic lattice images of the square regions in Figure $2 \mathbf{E}$ obtained by inverse fast Fourier transform (IFFT). The fringe spacings of $0.200 \mathrm{~nm}$ in Figure $2 \mathbf{F}$ and $0.210 \mathrm{~nm}$ in Figure 2G correspond to (121) plane of $\mathrm{LiBH}_{4}$ and (111) plane of $\mathrm{Ni}$, respectively. The TEM results reveal that $\mathrm{LiBH}_{4}$ and np-Ni indeed co-existed in the sample.

\section{Thermal Dehydrogenation Characteristics of $\mathrm{LiBH}_{4} / \mathrm{np}-\mathrm{Ni}$ System}

Figure 4 shows the temperature-programmed dehydrogenation curves of the $\mathrm{LiBH}_{4} / \mathrm{np}-\mathrm{Ni}$ (1:5) system and pristine $\mathrm{LiBH}_{4}$. It can be seen that hydrogen release from the $\mathrm{LiBH}_{4} / \mathrm{np}-\mathrm{Ni}$ (1:5) system initiates at about $70^{\circ} \mathrm{C}$ and ends before $400^{\circ} \mathrm{C}$, with $\sim 11.9$ wt. $\%$ of hydrogen desorbed. In contrast, the starting dehydrogenation temperature is as high as $330^{\circ} \mathrm{C}$ for pristine $\mathrm{LiBH}_{4}$, and only 3.5 wt.\% of hydrogen can be released when heating to $500^{\circ} \mathrm{C}$. Evidently, the thermal dehydrogenation stability of $\mathrm{LiBH}_{4}$ was notably reduced by np-Ni. In addition, Table 3 compares the dehydrogenation temperature of $\mathrm{LiBH}_{4}$ supported on different

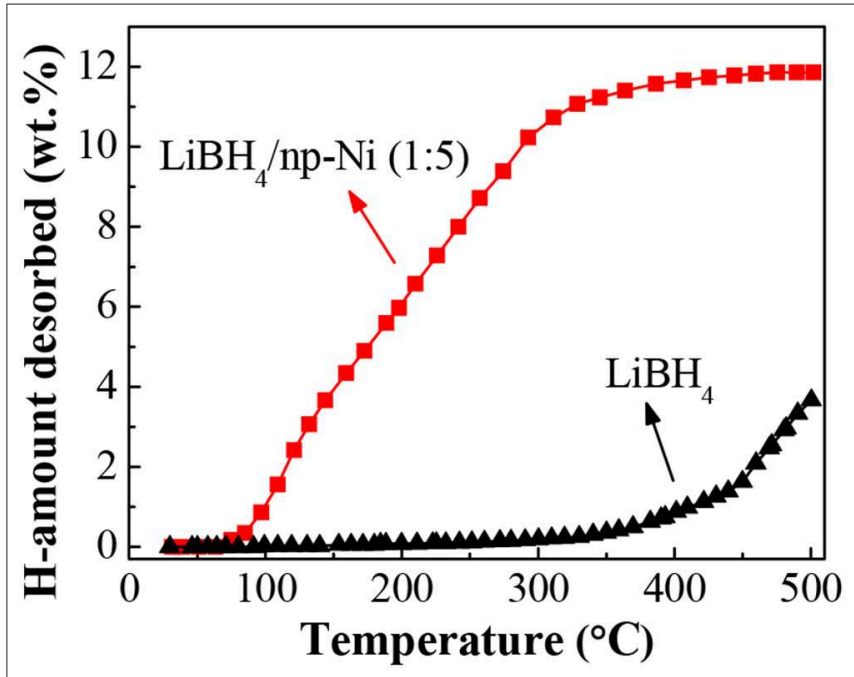

FIGURE 4 | Hydrogen desorption curves of the $\mathrm{LiBH}_{4} / \mathrm{np}-\mathrm{Ni}(1: 5)$ system and pristine $\mathrm{LiBH}_{4}$.

carriers. It is observed that the present $\mathrm{LiBH}_{4} / \mathrm{np}-\mathrm{Ni}(1: 5)$ system has lower starting and ending dehydrogenation temperatures as compared with the reported $\mathrm{LiBH}_{4}$-based supporting systems. In other words, np-Ni can provide a stronger destabilization effect on $\mathrm{LiBH}_{4}$ relative to other carriers due to its synergistic effect of nanoconfinement and metallic catalysis. On the one hand, nanoconfinement of $\mathrm{LiBH}_{4}$ in $\mathrm{np}-\mathrm{Ni}$ can decrease the particle size to nanoscale level, which is very helpful to facilitate the dehydrogenation by enlarging the reaction interface and shortening the element diffusion distance. On the other hand, $\mathrm{Ni}$ itself can act as the dehydrogenation catalyst for $\mathrm{LiBH}_{4}$ by enhancing charge donation ability of $\mathrm{Li}$ atom to $\mathrm{BH}_{4}$ unit and thus weakening the $\mathrm{B}-\mathrm{H}$ bond due to its high electronegativity.

To further monitor the dehydrogenation process, Figure 5 gives the FTIR spectra of $\mathrm{LiBH}_{4} / \mathrm{np}-\mathrm{Ni}$ (1:5) systems after dehydrogenation at different temperatures. As can be seen 
TABLE 3 | Hydrogen desorption temperature of $\mathrm{LiBH}_{4}$ with different carriers.

\begin{tabular}{|c|c|c|c|}
\hline Carriers & $\begin{array}{l}\text { Starting } \\
\text { temperature } \\
\left({ }^{\circ} \mathrm{C}\right)\end{array}$ & $\begin{array}{l}\text { Ending } \\
\text { temperature } \\
\left({ }^{\circ} \mathrm{C}\right)\end{array}$ & References \\
\hline $\mathrm{ZnO} / \mathrm{ZnCo}_{2} \mathrm{O}_{4}$ & 169 & $<500$ & Xu et al., 2017 \\
\hline CMK-3 & 220 & $<600$ & Zhang et al., 2007 \\
\hline $\begin{array}{l}\text { Carbon } \\
\text { aerogels@CoNiB }\end{array}$ & 192 & 600 & Zhao et al., 2014 \\
\hline SBA-15 & 150 & $>500$ & $\begin{array}{l}\text { Ngene et al., } \\
2010 a\end{array}$ \\
\hline $\begin{array}{l}\text { Single-walled } \\
\text { carbon } \\
\text { nanotubes }\end{array}$ & 270 & 550 & Fang et al., $2008 \mathrm{a}$ \\
\hline $\begin{array}{l}\text { Carbon } \\
\text { nanotubes }\end{array}$ & 250 & $<600$ & Yu et al., 2007 \\
\hline $\begin{array}{l}\text { Nanoporous } \\
\text { carbon }\end{array}$ & 220 & 420 & Liu et al., 2010 \\
\hline Nanoscale $\mathrm{SiO}_{2}$ & 200 & 500 & Chen et al., 2010 \\
\hline $\mathrm{np}-\mathrm{Ni}$ & 70 & 400 & This work \\
\hline
\end{tabular}

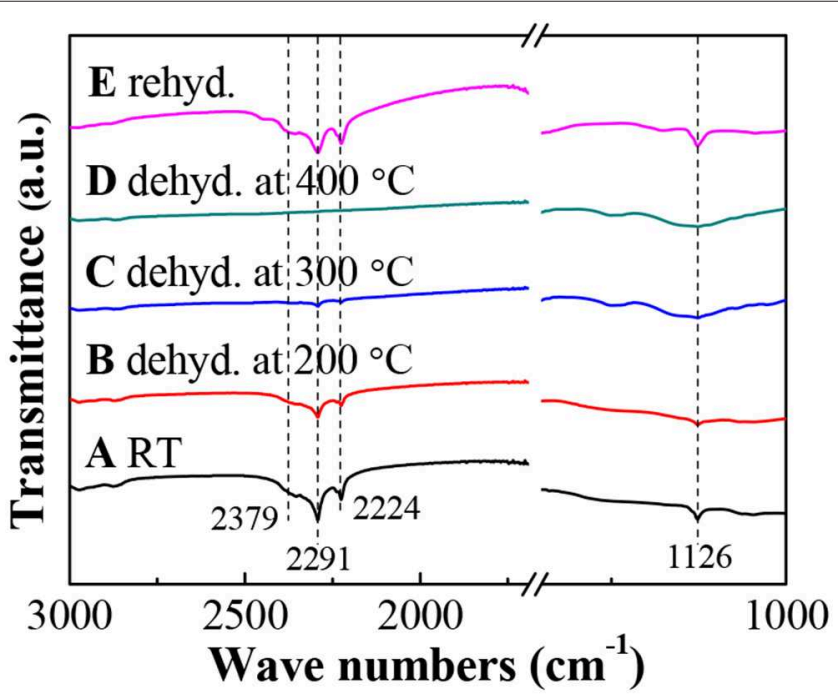

FIGURE 5 | FTIR spectra of the $\mathrm{LiBH}_{4} / \mathrm{np}-\mathrm{Ni}(1: 5)$ system dehydrogenated at different temperatures and rehydrogenated.

in Figure 5A, the obvious characteristic bands for $\mathrm{B}-\mathrm{H}$ bond vibrations located at 2,379, 2,291, 2,224 and 1,126 $\mathrm{cm}^{-1}$ (Zhang et al., 2011) confirm the existence of $\mathrm{LiBH}_{4}$. With increasing the dehydrogenation temperature, the band intensity of $\mathrm{B}-\mathrm{H}$ bond vibrations decreases gradually, indicating a continuous consumption of $\mathrm{LiBH}_{4}$. Moreover, almost no FTIR bands can be observed in Figure 5D, which means that $\mathrm{LiBH}_{4}$ was almost completely decomposed at $400^{\circ} \mathrm{C}$. This result is in good agreement with the dehydrogenation phenomenon shown in Figure 4.

\section{Dehydrogenation Kinetics of $\mathrm{LiBH}_{4} / \mathrm{np}-\mathrm{Ni}$ Systetm}

Figure 6A presents the isothermal dehydrogenation curves of the $\mathrm{LiBH}_{4} / \mathrm{np}-\mathrm{Ni}(1: 5)$ system at the temperatures of 250,300 , and $350^{\circ} \mathrm{C}$, respectively. It is observed that the dehydrogenation rate increases as the temperature rises. For example, the amounts of hydrogen desorbed within $5 \mathrm{~min}$ are $7.3,9.4$, and $10.4 \mathrm{wt} . \%$ at 250,300 , and $350^{\circ} \mathrm{C}$, respectively. In order to further reveal the dehydrogenation mechanism, the experimental dehydrogenation data were fitted by the kinetic modeling of $g(\alpha)=\int d \alpha / f(\alpha)=k t$, where $\alpha$ is the reacted fraction at time $t, g(\alpha)$ and $f(\alpha)$ are the functions representing different reaction mechanisms, and $k$ is the rate constant (Li Y. et al., 2011; Liu D. M. et al., 2013). As the result, the function of $-\ln (1-\alpha)$ gives the best linearity (see Figure 6B) over a broader $\alpha$ range for each measurement with the correlation coefficient of $R^{2}>0.99$. This result indicates that dehydrogenation of the $\mathrm{LiBH}_{4} / \mathrm{np}-\mathrm{Ni}$ (1:5) system follows the first-order mechanism in the investigated temperature range.

According to the slope of the fitted straight line in Figure $6 \mathbf{B}$, the $k$ value at different temperatures can be obtained. Then the apparent activation energy for hydrogen desorption $\left(E_{\mathrm{a}}\right)$ can be determined based on the Arrhenius equation of $k=$ $k_{0} \cdot \exp \left[-E_{\mathrm{a}} /(R T)\right]$, where $k_{0}$ is the pre-exponential factor, $R$ is the gas constant, and $T$ is the temperature. Figure $6 \mathrm{C}$ gives the Arrhenius plot for the $\mathrm{LiBH}_{4} / \mathrm{np}-\mathrm{Ni}$ (1:5) system. From the slope $\left(-E_{\mathrm{a}} / R\right)$ of the fitted straight line, $E_{\mathrm{a}}$ was calculated to be $11.4 \mathrm{~kJ} / \mathrm{mol}$. As reported in the literatures that $E_{\mathrm{a}}$ for $\mathrm{LiBH}_{4}$ supported on CMK-3 and carbon aerogels@CoNiB are 40 and $46.39 \mathrm{~kJ} / \mathrm{mol}$, respectively (Zhang et al., 2007; Zhao et al., 2014). The lower $E_{\mathrm{a}}$ value for the present $\mathrm{LiBH}_{4} / \mathrm{np}-\mathrm{Ni}$ (1:5) system is originating from the synergistic effect of nanoconfinement and metallic catalysis of $\mathrm{np}-\mathrm{Ni}$, and can be regarded as one of the most important reasons for the enhanced dehydrogenation properties shown in Figures 4, 6A. Moreover, the preparation process of np$\mathrm{Ni}$ carrier for $\mathrm{LiBH}_{4}$ by dealloying method is far more convenient than that of CMK-3 based on template method.

\section{Rehydrogenation Characteristics of $\mathrm{LiBH}_{4} / \mathrm{np}-\mathrm{Ni}$ System}

The dehydrogenated residue of the $\mathrm{LiBH}_{4} / \mathrm{np}-\mathrm{Ni}$ (1:5) system was subjected to rehydrogenation, and Figure 7 demonstrates the isothermal rehydrogenation curve. It is observed that the $\mathrm{LiBH}_{4} / \mathrm{np}-\mathrm{Ni}$ (1:5) system can readily reabsorb 8.3 wt.\% of hydrogen at $450^{\circ} \mathrm{C}$ under $8 \mathrm{MPa}$ hydrogen pressure. The FTIR spectrum for the rehydrogenated product shown in Figure 5E suggests that $\mathrm{LiBH}_{4}$ was regenerated. The inset of Figure 7 gives the second hydrogen desorption curve of the $\mathrm{LiBH}_{4} / \mathrm{np}-\mathrm{Ni}(1: 5)$ system. It can be seen that $\sim 8.2$ wt.\% of hydrogen can be released during the second dehydrogenation process. Note that the starting dehydrogenation temperature keeps in a low value of about $60^{\circ} \mathrm{C}$. The result indicates undoubtedly that the synergistic effect of nanoconfinement and metallic catalysis of np-Ni maintains well upon repeated dehydrogenation/hydrogenation.

\section{CONCLUSIONS}

In order to improve the hydrogen storage properties of $\mathrm{LiBH}_{4}$, the nanoporous Ni-based alloy was prepared by dealloying of the precursor $\mathrm{Mn}_{70} \mathrm{Ni}_{30}$ alloy and then used as the carrier to support $\mathrm{LiBH}_{4}$ by wet impregnation method. It was found that the constructed $\mathrm{LiBH}_{4} / \mathrm{np}-\mathrm{Ni}(1: 5)$ system can release $\sim 11.9$ 

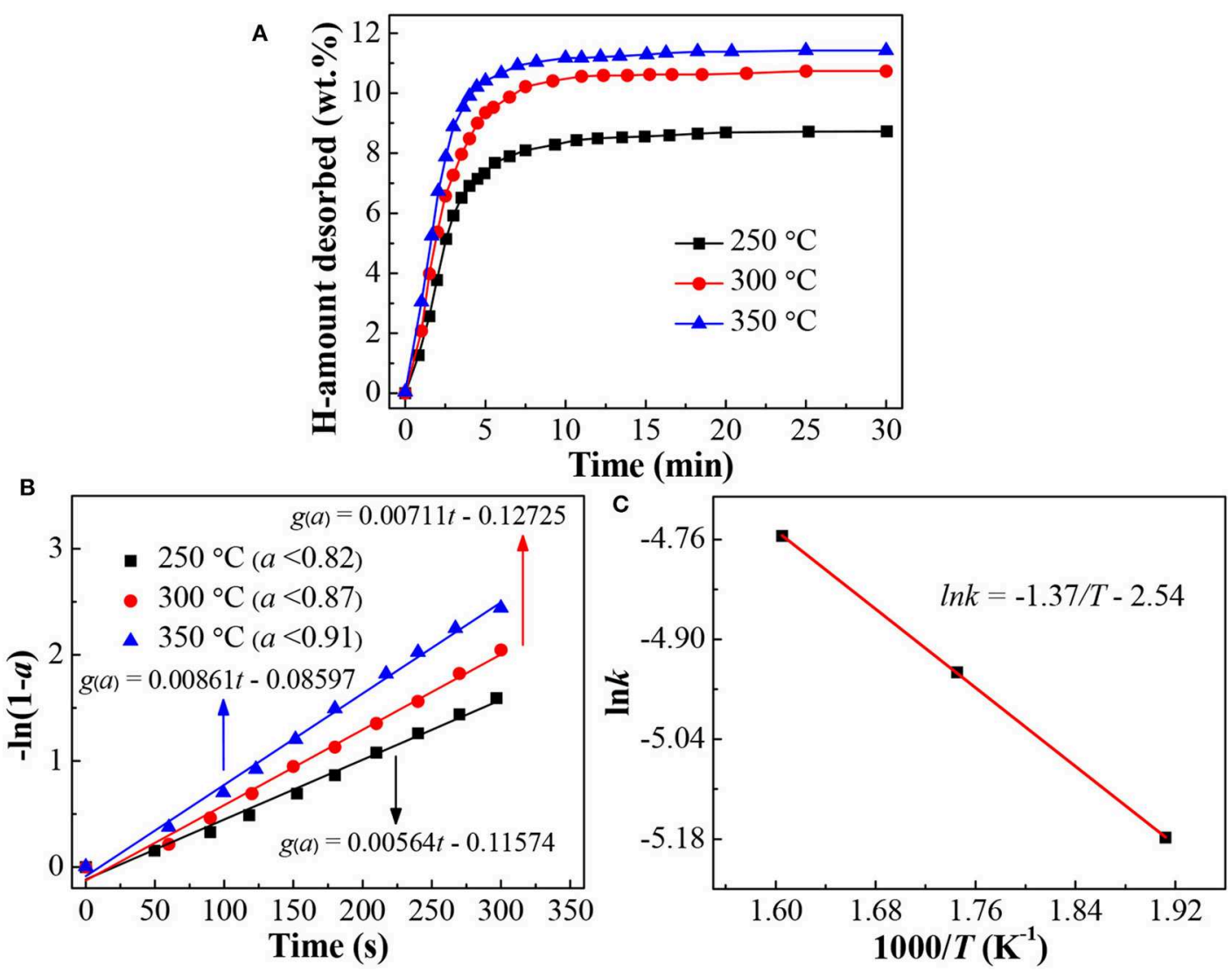

FIGURE 6 | (A) Isothermal dehydrogenation curves, (B) Plots of $-\ln (1-a)$ vs. $t$ at different temperatures, and (C) Arrhenius plot for the dehydrogenation of the $\mathrm{LiBH}_{4} / \mathrm{np}-\mathrm{Ni}(1: 5)$ system.

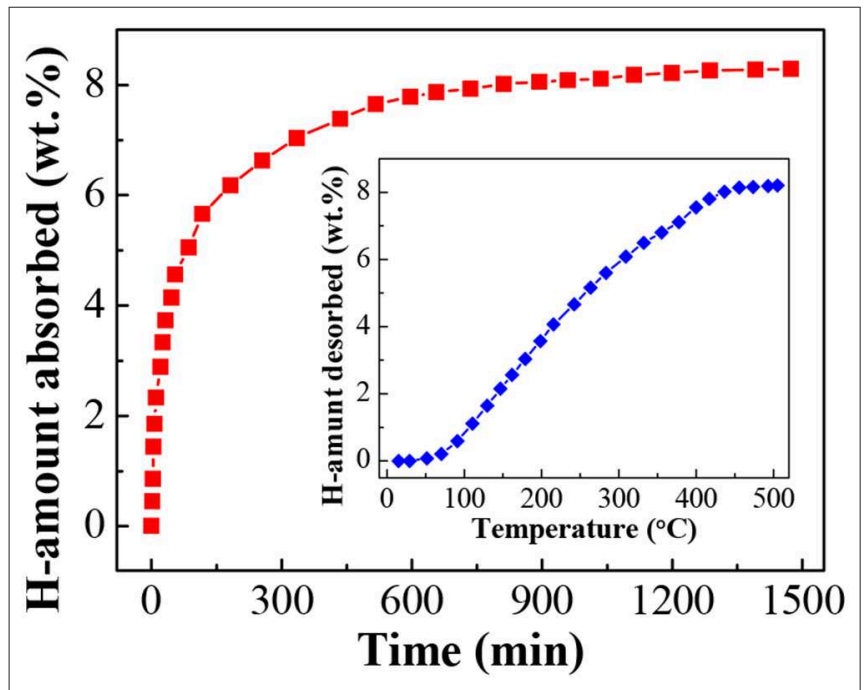

FIGURE 7 | Isothermal rehydrogenation curve of the $\mathrm{LiBH}_{4} / \mathrm{np}-\mathrm{Ni}$ (1:5) system. Inset shows the second hydrogen desorption curve.

wt.\% of hydrogen with the starting and ending dehydrogenation temperatures as low as about 70 and $400^{\circ} \mathrm{C}$, respectively. Due to the synergistic effect of nanoconfinement and metallic catalysis of nanoporous Ni-based alloy, the apparent dehydrogenation activation energy of $\mathrm{LiBH}_{4}$ was remarkable decreased to about $11.4 \mathrm{~kJ} / \mathrm{mol}$. The dehydrogenated residue can readily absorb hydrogen to regenerate $\mathrm{LiBH}_{4}$ at $450^{\circ} \mathrm{C}$ under $8 \mathrm{MPa}$ hydrogen pressure. Moreover, the starting dehydrogenation temperature keeps in a low value of about $60^{\circ} \mathrm{C}$ during the second dehydrogenation process.

\section{DATA AVAILABILITY STATEMENT}

All datasets generated for this study are included in the article.

\section{AUTHOR CONTRIBUTIONS}

$\mathrm{XC}$ and DL contributed conception and design of the study. $\mathrm{XC}$ and $\mathrm{YZ}$ were in charge of the analysis of data. ZL and $\mathrm{CW}$ prepared samples and performed characterization. All authors contributed to manuscript revision, read, and approved the submitted version.

\section{FUNDING}

This work was supported by the National Natural Science Foundation of China (Nos. U1503192 and 51371008). 


\section{REFERENCES}

Abdalla, A. M., Hossain, S., Nisfindy, O. B., Azad, A. T., Dawood, M., and Azad,. A. K. (2018). Hydrogen production, storage, transportation and key challenges with applications: a review. Energ. Convers. Manage. 165, 602-627. doi: 10.1016/j.enconman.2018.03.088

Abe, J. O., Popoola, A. P. I., Ajenifuja, E., and Popoola, O. M. (2019). Hydrogen energy, economy and storage: review and recommendation. Inter. J. Hydr. Energy 44, 15072-15086. doi: 10.1016/j.ijhydene.2019.04.068

Cai, R., Sun, L. X., Xu, F., Zou, Y. J., and Chu, H. L. (2016). $\mathrm{LiBH}_{4}$ confined in nitrogen-doped ordered mesoporous carbons for hydrogen storage. Mater. Sci. Forum 852, 858-863. doi: 10.4028/www.scientific.net/MSF. 852.858

Cai, W., Hou, J., Tao, P., and Yang, Y. (2018). An insight into the dehydrogenation behaviour of $\mathrm{LiBH}_{4}$ exhibiting remarkable kinetics enhanced by nanostructured h-BN. J. Alloy Compd. 750, 443-450. doi: 10.1016/j.jallcom.2018.04.022

Chen, X. Y., Guo, Y. H., Gao, L., and Yu, X. B. (2010). Improved dehydrogenation of $\mathrm{LiBH}_{4}$ supported on nanoscale $\mathrm{SiO}_{2}$ via liquid phase method. J. Mater. Res. 25, 2415-2421. doi: 10.1557/JMR.2010.0301

Ding, Z., Wu, P., and Shaw, L. (2019). Solid-state hydrogen desorption of $2 \mathrm{MgH}_{2}$ $+\mathrm{LiBH}_{4}$ nano-mixture: a kinetics mechanism study. J. Alloy Compd. 806, 350-360. doi: 10.1016/j.jallcom.2019.07.218

Fang, Z. Z., Kang, X. D., Wang, P., and Cheng, H. M. (2008a). Improved reversible dehydrogenation of lithium borohydride by milling with asprepared single-walled carbon nanotubes. J. Phys. Chem. C 112, 17023-17029. doi: $10.1021 /$ jp803916k

Fang, Z. Z., Kang, X. D., Yang, Z. X., Walker, G. S., and Wang, P. (2011). Combined effects of functional cation and anion on the reversible dehydrogenation of $\mathrm{LiBH}_{4}$. J. Phys. Chem. C 115, 11839-11845. doi: 10.1021/jp2 $00137 \mathrm{n}$

Fang, Z. Z., Wang, P., Rufford, T. E., Kang, X. D., Lu, G. Q., and Cheng, H. M. (2008b). Kinetic- and thermodynamic-based improvements of lithium borohydride incorporated into activated carbon. Acta Mater. 56, 6257-6263. doi: 10.1016/j.actamat.2008.08.033

Gasnier, A., Luguet, M., Pereira, A. G., Troiani, H., Zampieri, G., and Gennari, F. C. (2019). Entanglement of N-doped graphene in resorcinol-formaldehyde: Effect over nanoconfined $\mathrm{LiBH}_{4}$ for hydrogen storage. Carbon 147, 284-294. doi: 10.1016/j.carbon.2019.02.090

Guo, L., Li, Y., Ma, Y., Liu, Y., Peng, D., Zhang, L., et al. (2017). Enhanced hydrogen storage capacity and reversibility of $\mathrm{LiBH}_{4}$ encapsulated in carbon nanocages. Inter. J. Hydr. Energy 42, 2215-2222. doi: 10.1016/j.ijhydene.2016.11.184

Izumi, F., and Ikeda, T. (2000). A rietveld-analysis programm RIETAN98 and its applications to zeolites. Mater. Sci. Forum 321-324, 198-205. doi: 10.4028/www.scientific.net/MSF.321-324.198

Li, C., Peng, P., Zhou, D. W., and Wan, L. (2011). Research progress in $\mathrm{LiBH}_{4}$ for hydrogen storage: a review. Inter. J. Hydrogen Energy 36, 14512-14526. doi: 10.1016/j.ijhydene.2011.08.030

Li, H. W., Yan, Y. G., Orimo, S., Züttel, A., and Jensen, C. M. (2011). Recent progress in metal borohydrides for hydrogen storage. Energies 4, 185-214. doi: $10.3390 /$ en 4010185

Li, Y., Zhou, G., Fang, F., Yu, X., Zhang, Q., Ouyang, L., et al. (2011). De-/rehydrogenation features of $\mathrm{NaAlH}_{4}$ confined exclusively in nanopores. Acta Mater. 59, 1829-1838. doi: 10.1016/j.actamat.2010.11.049

Liu, D. M., Huang, W. J., Si, T. Z., and Zhang, Q. A. (2013). Hydrogen storage properties of $\mathrm{LiBH}_{4}$ destabilized by $\mathrm{SrH}_{2}$. J. Alloy Compd. 551, 8-11. doi: 10.1016/j.jallcom.2012.09.138

Liu, D. M., Tan, Q. J., Gao, C., Sun, T., and Li, Y. T. (2015). Reversible hydrogen storage properties of $\mathrm{LiBH}_{4}$ combined with hydrogenated $\mathrm{Mg}_{11} \mathrm{CeNi}$ alloy. Inter. J. Hydr. Energy 40, 6600-6605. doi: 10.1016/j.ijhydene.2015. 03.130

Liu, H., Wang, X., Zhou, H., Gao, S., Ge, H., Li, S., et al. (2016). Improved hydrogen desorption properties of $\mathrm{LiBH}_{4}$ by $\mathrm{AlH}_{3}$ addition. Inter. J. Hydrogen Energy 41, 22118-22127. doi: 10.1016/j.ijhydene.2016.09.177

Liu, X. F., Peaslee, D., Jost, C. Z., and Majzoub, E. H. (2010). Controlling the decomposition pathway of $\mathrm{LiBH}_{4}$ via confinement in highly ordered nanoporous carbon. J. Phys. Chem. C 114, 14036-14041. doi: $10.1021 /$ jp 1055045
Liu, Y., Heere, M., Vasquez, L. C., Paterakis, C., Sørby, M. H., Hauback, B. C., et al. (2018). Dehydrogenation and rehydrogenation of a $0.62 \mathrm{LiBH}_{4}-0.38 \mathrm{NaBH}_{4}$ mixture with nano-sized Ni. Inter. J. Hydrogen Energy 43, 16782-16792. doi: 10.1016/j.ijhydene.2018.04.211

Lowell, S., Shields, J. E., Thomas, M. A., and Thommes, M. (2004). Characterization of Porous Solids and Powders: Surface Area, Pore Size and Density. Dordrecht: Springer.

Mauron, P., Buchter, F., Friedrichs, O., Remhof, A., Bielmann, M., Zwicky, C. N., et al. (2008). Stability and reversibility of $\mathrm{LiBH}_{4}$. J. Phys. Chem. B 112, 906-910. doi: $10.1021 /$ jp077572r

Meng, X., Wan, C., Wang, Y., and Ju, X. (2018). Porous Ni@C derived from bimetallic metal-organic frameworks and its application for improving $\mathrm{LiBH}_{4}$ dehydrogenation. J. Alloy Compd. 735, 1637-1647. doi: 10.1016/j.jallcom.2017.11.191

Ngene, P., Adelhelm, P., Beale, A. M., de Jong, K. P., and de Jong, P. E. (2010a). $\mathrm{LiBH}_{4} / \mathrm{SBA}-15$ nanocomposites prepared by melt infiltration under hydrogen pressure: synthesis and hydrogen sorption properties. J. Phys. Chem. C 114, 6163-6168. doi: 10.1021/jp9065949

Ngene, P., van Zwienen, M. R., and de Jongh, P. E. (2010b). Reversibility of the hydrogen desorption from $\mathrm{LiBH}_{4}$ : a synergetic effect of nanoconfinement and $\mathrm{Ni}$ addition. Chem. Commun. 46, 8201-8203. doi: 10.1039/c0cc $03218 \mathrm{~b}$

Ngene, P., Verkuijlen, M. H., Zheng, Q., Kragten, J., Bentum, P. J. M., Bitter, J. H., et al. (2011). The role of $\mathrm{Ni}$ in increasing the reversibility of the hydrogen release from nanoconfined $\mathrm{LiBH}_{4}$. Faraday Discuss. 151, 47-58. doi: $10.1039 / \mathrm{COFD} 00028 \mathrm{~K}$

Orimo, S., Nakamori, Y., Kitahara, G., Miwa, K., Ohba, N., Towata, S., et al. (2005). Dehydriding and rehydriding reactions of $\mathrm{LiBH}_{4}$. J. Alloy Compd. 404, 427-430. doi: 10.1016/j.jallcom.2004.10.091

Shao, J., Xiao, X., Fan, X., Huang, X., Zhai, B., Li, S., et al. (2015). Enhanced hydrogen storage capacity and reversibility of $\mathrm{LiBH}_{4}$ nanoconfined in the densified zeolite-templated carbon with high mechanical stability. Nano Energy 15, 244-255. doi: 10.1016/j.nanoen.2015.04.023

Sun, W. W., Li, S. F., Mao, J. F., Guo, Z. P., Liu, H. K., Dou, S. X., et al. (2011). Nanoconfinement of lithium borohydride in Cu-MOFs towards low temperature dehydrogenation. Dalton Trans. 40, 5673-5676. doi: $10.1039 / \mathrm{c} 0 \mathrm{dt} 01727 \mathrm{~b}$

Surrey, A., Minella, C. B., Fechler, N., Antonietti, M., Grafe, H. J., Schultz, L., et al. (2016). Improved hydrogen storage properties of $\mathrm{LiBH}_{4}$ via nanoconfinement in micro-and mesoporous aerogel-like carbon. Inter. J. Hydr. Energy 41, 5540-5548. doi: 10.1016/j.ijhydene.2016.01.163

Xu, X. H., Zang, L., Zhao, Y. R., Zhao, Y., Wang, Y. J., and Jiao, L. F. (2017). Hydrogen storage behavior of $\mathrm{LiBH}_{4}$ improved by the confinement of hierarchical porous $\mathrm{ZnO} / \mathrm{ZnCo}_{2} \mathrm{O}_{4}$ nanoparticles. J. Power Sources 359, 134-141. doi: 10.1016/j.jpowsour.2017.05.047

Yang, J., Sudik, A., Wolverton, C., and Siegel, D. J. (2010). High capacity hydrogen storage materials: attributes for automotive applications and techniques for materials discovery. Chem. Soc. Rev. 39, 656-675. doi: 10.1039/b80 $2882 \mathrm{f}$

Yin, L., Wang, P., Fang, Z., and Cheng, H. (2008). Thermodynamically tuning $\mathrm{LiBH}_{4}$ by fluorine anion doping for hydrogen storage: a density functional study. Chem. Phys. Lett. 450, 318-321. doi: 10.1016/j.cplett.2007. 11.060

Yu, X. B., Wu, Z., Chen, Q. R., Li, Z. L., Weng, B. C., and Huang, T. S. (2007). Improved hydrogen storage properties of $\mathrm{LiBH}_{4}$ destabilized by carbon. Appl. Phys. Lett. 90:034106. doi: 10.1063/1.2432240

Zhang, B. J., Liu, B. H., and Li, Z. P. (2011). Destabilization of $\mathrm{LiBH}_{4}$ by $(\mathrm{Ce}, \mathrm{La})(\mathrm{Cl}, \mathrm{F})_{3}$ for hydrogen storage. J. Alloy Compd. 509, 751-757. doi: 10.1016/j.jallcom.2010.09.066

Zhang, L., Zheng, J., Xiao, X., Wang, X., Huang, X., Liu, M., et al. (2017). A new strategy to remarkably improve the low-temperature reversible hydrogen desorption performances of $\mathrm{LiBH}_{4}$ by compositing with fluorographene. Inter. J. Hydr. Energy 42, 20046-20055. doi: 10.1016/j.ijhydene.2017. 05.060

Zhang, Y., Liu, Y., Yang, Y., Li, Y., Hu, J., Gao, M., et al. (2018). Superior catalytic activity of in situ reduced metallic Co for hydrogen storage in a $\mathrm{Co}(\mathrm{OH})_{2}$-containing $\mathrm{LiBH}_{4} / 2 \mathrm{LiNH}_{2}$ composite. Mater. Res. Bull. 97, 544-552. doi: 10.1016/j.materresbull.2017.09.037 
Zhang, Y., Zhang, W. S., Wang, A. Q., Sun, L. X., Fan, M. Q., Chu, H. L., et al. (2007). $\mathrm{LiBH}_{4}$ nanoparticles supported by disordered mesoporous carbon: Hydrogen storage performances and destabilization mechanisms. Inter. J. Hydr. Energy 32, 3976-3980. doi: 10.1016/j.ijhydene.2007.04.010

Zhao, Y. P., Jiao, L. F., Liu, Y. C., Guo, L. J., Li, L., Liu, H. Q., et al. (2014). A synergistic effect between nanoconfinement of carbon aerogels and catalysis of CoNiB nanoparticles on dehydrogenation of $\mathrm{LiBH}_{4}$. Inter. J. Hydr. Energy 39, 917-926. doi: 10.1016/j.ijhydene.2013.10.137

Züttel, A., Rentsch, S., Fischer, P., Wenger, P., Sudan, P., Mauron, P.h., et al. (2003). Hydrogen storage properties of $\mathrm{LiBH}_{4}$. J. Alloy Compd. 356, 515-520. doi: 10.1016/s0925-8388(02)01253-7
Conflict of Interest: The authors declare that the research was conducted in the absence of any commercial or financial relationships that could be construed as a potential conflict of interest.

Copyright $\odot 2020$ Chen, Li, Zhang, Liu, Wang, Li, Si and Zhang. This is an openaccess article distributed under the terms of the Creative Commons Attribution License (CC BY). The use, distribution or reproduction in other forums is permitted, provided the original author(s) and the copyright owner(s) are credited and that the original publication in this journal is cited, in accordance with accepted academic practice. No use, distribution or reproduction is permitted which does not comply with these terms. 